\title{
The enamelling of concrete for improved performance characteristics by means of high power diode laser interaction
}

\author{
J. Lawrence and L. Li \\ Manufacturing Division, Department of Mechanical Engineering, \\ University of Manchester Institute of Science and Technology (UMIST), PO Box 88, Manchester M60 1QD, UK
}

\begin{abstract}
The contemporary $120 \mathrm{~W}$ high power diode laser (HPDL) has been successfully used for the first time to fire an enamel glaze onto the ordinary Portland cement (OPC) surface of concrete. The enamel glazes were generated with laser power densities as low as $1 \mathrm{~kW} / \mathrm{cm}^{2}$ and at speeds of up to $780 \mathrm{~mm} / \mathrm{min}$, yielding a possible maximum coverage rate of $0.34 \mathrm{~m} / \mathrm{h}$. The enamel glazes were typically $750 \mu \mathrm{m}$ in thickness and displayed no discernible microcracks or porosities. Owing to the wettability characteristics of the OPC, it proved necessary to laser treat the OPC surface prior to firing the enamel. Mechanical testing of the HPDL fired enamel glazes revealed that the average rupture strength was $2.8 \mathrm{~J}$, whilst the rupture strength of the untreated OPC surface was some $4.3 \mathrm{~J}$. The average bond strength of the glaze was recorded as $2.4 \mathrm{MPa}$ as opposed to $6.3 \mathrm{MPa}$ for the untreated OPC. The HPDL fired enamel glazes exhibited exceptional wear and corrosion resistance, wearing by only $3.3 \mathrm{mg} / \mathrm{cm}^{2}$ after $8 \mathrm{~h}$ and showing no discernible morphological or microstructural changes when exposed to acid, alkali and detergent. In contrast, the untreated OPC surface was attacked almost immediately by the reagents used and was worn by $78 \mathrm{mg} / \mathrm{cm}^{2}$ after $8 \mathrm{~h}$. In addition, the HPDL fired enamel glaze afforded the concrete bulk complete resistance to water absorption. The findings of life assessment testing revealed that the HPDL fired enamel glaze effected an increase in the wear life of the concrete by 4.5 to 52.7 times over an untreated OPC surface, depending on the corrosive environment.
\end{abstract}

Keywords: high power diode laser (HPDL); concrete; ordinary Portland cement (OPC); enamel; glazing; wettability; bonding; wear life

\section{Introduction}

The unique characteristics of lasers furnishes them with the ability to be employed for the non-contact processing of materials which are otherwise difficult to process. Concrete is one such material since it is a composite, consisting of an array of fine and coarse aggregate pieces embedded within an ordinary Portland cement (OPC) matrix. Consequently the processing and surface treatment of concrete can be extremely laborious. This present work describes the utilisation of a high power diode laser (HPDL) to produce for the first time an enamelled glaze on the 'as-cast' OPC surface of concrete and the effects thereof on the OPC's mechanical, chemical and physical properties. The paper reports on the testing of both the untreated OPC surface and the laser generated enamel glaze in terms of bond strength, compressive strength, surface roughness, water sorptivity, wear life characteristics and corrosion resistance. In addition, the optimum laser parameters operating window is established, as well as the achievable coverage rates. The value of such an investigation would be to facilitate the hitherto impossible task of generating a durable and long-lasting surface seal on the OPC surface of the concrete, thereby extending the life and applications base of the concrete. It is a distinct possibility that such develops may yield significant economic benefits.

The laser processing of concrete is a field of ongoing research, with many studies having been carried out to investigate the technique itself and the associated phenomena. Most of the research, however, has concentrated on the laser cutting of concrete and reinforced concrete using high power $\mathrm{CO}_{2}$ lasers, most prominently with regard to nuclear reactor decommissioning [1-3]. Also, as part of nuclear plant decommissioning, Li et al. [47] conducted research to determine the workability of several laser techniques for sealing/fixing radioactive contamination onto concrete surfaces. Such techniques experimented with were: direct glazing of the concrete, single and multiple layer fusion cladding and combined chemical/fusion cladding. Work by Sugimoto et al. [8] focused upon modifying the surface appearance and surface properties of cement based materials using a high power $\mathrm{CO}_{2}$ laser. The laser treatment produced novel surfaces, with surface textures, properties and appearance unique to laser treatment. The resultant physical characteristics and mechanical behaviour of the post-process cement based materials 
was later fully characterised by Wignarajah et al. [9]. Borodina et al. [10] has carried out investigations into the structural changes within the composition of zirconia concrete caused by surface exposure to $\mathrm{CO}_{2}$ laser radiation, detailing microstructural changes, phase changes and the absorptivity characteristics. In all of these studies, spallation and excessive cracking and porosity formation were found to be major problems undermining the performance of the laser treated surface layer. However, Lawrence and $\mathrm{Li}$ [11-14] have treated the OPC surface of concrete with both $\mathrm{CO}_{2}$ and HPDLs. The HPDL generated OPC glaze was shown to be more than an effective surface modification insofar as it provided superior mechanical, physical and chemical characteristics over an untreated or $\mathrm{CO}_{2}$ laser treated OPC surface.

To date very little published work exists pertaining to the use of lasers for altering the surface properties of materials in order to improve their wettability characteristics. Notwithstanding this, it is recognised within the currently published work that laser irradiation of a metal surface can bring about changes in the metal's wettability characteristics. Previously Zhou et al. $[15,16]$ carried out work on the laser coating of aluminium alloys with ceramic materials $\left(\mathrm{SiO}_{2}, \mathrm{Al}_{2} \mathrm{O}_{3}\right.$, etc.), reporting on the well documented fact that generated oxide layers often promote metal/oxide wetting. Further, Heitz et al. [17], Henari et al. [18] and Olfert et al. [19] have found that excimer laser treatment of metals results in improved coating adhesion. The improvements in adhesion were attributed to the fact that the excimer laser treatment resulted in a smoother surface and as such enhanced the action of wetting. Yet the reasons for these changes with regard to changes in the material's surface morphology, surface composition and surface energy are not reported. However, in a number of more comprehensive investigations by Lawrence et al., which compared the effects of $\mathrm{CO}_{2}, \mathrm{Nd}: \mathrm{YAG}$, excimer and HPDL radiation on the wettability characteristics of a mild steel $[20,21]$ and a $\mathrm{SiO}_{2} / \mathrm{Al}_{2} \mathrm{O}_{3}$-based ceramic material [22], it was found that changes in the wettability characteristics of the steel varied depending upon the laser type. Furthermore Lawrence et al. have conducted numerous studies to investigate the feasibility and characteristics of laser enamelling ceramic materials [23-26] and steels $[27,28]$.

\section{Experimental Procedures}

\subsection{Materials}

The concrete studied in the experiments was the ubiquitous OPC based concrete. For the purpose of experimental convenience the as-received concrete blocks were sectioned into squares $\left(120 \times 120 \times 20 \mathrm{~mm}^{3}\right)$ prior to laser treatment. The composition by volume of the concrete is as follows: $20 \mathrm{~mm}$ limestone aggregate $(40 \%), 10 \mathrm{~mm}$ limestone aggregate $(14 \%)$, zone $\mathrm{M}$ sand $(28.5 \%)$, OPC $(10.5 \%)$ and particulate fine aggregate $(7 \%)$. In order to obtain results of a practical and useful nature, the area of the concrete irradiated during the experiments was the naturally occurring 'as cast' OPC surface of concrete. In this case the OPC surface of the concrete had a thickness of 2.5 $\mathrm{mm}$. The composition by volume of the OPC is as follows: $\mathrm{CaO}$ (63.9\%), $\mathrm{SiO}_{2}(21.9 \%), \mathrm{Al}_{2} \mathrm{O}_{3}(5.7 \%), \mathrm{Fe}_{2} \mathrm{O}_{3}(2.8 \%), \mathrm{SO}_{3}(2.7 \%)$, $\mathrm{MgO}(2.2 \%), \mathrm{K}_{2} \mathrm{O}(0.7 \%)$ and $\mathrm{Na}_{2} \mathrm{O}(0.1 \%)$.

The enamel used was a commercially available enamel frit (Ferro, UK) which, in order to form a manageable paste, was mixed with $20 \mathrm{wt} \%$ white spirit. The composition of the enamel consisted mainly of the following: $\mathrm{SiO}_{2}, \mathrm{~B}_{2} \mathrm{O}_{3}, \mathrm{Na}_{2} \mathrm{O}, \mathrm{Mn}$ and small quantities of $\mathrm{Pb}, \mathrm{Ba}, \mathrm{MgO}, \mathrm{Al}_{2} \mathrm{O}_{3}$ and $\mathrm{Ni}$, whilst the powder size was less than $25 \mu \mathrm{m}$ medium size.

\subsection{Laser processing procedure}

The laser used in the study was a surgical HPDL (Diomed, UK), emitting at $810 \mathrm{~nm} \pm 20 \mathrm{~nm}$ and operating in the CW mode with rated optical powers ranging from $0-120 \mathrm{~W}$. The laser beam was delivered to the work area by means of a $4 \mathrm{~m}$ long, $600 \mu \mathrm{m}$ core diameter optical fibre, the end of which was connected to a $2: 1$ focusing lens assembly mounted on the z-axis of a 3 -axis $\mathrm{CNC}$ gantry table. The concrete sample blocks and the enamel frit were irradiated using the defocused high order mode HPDL beam with a beam spot diameter of $2-5 \mathrm{~mm}$ and laser powers (measured at the workpiece using a Power Wizard power meter) of 20-100 W. The defocused laser beam was fired across the surfaces of the concrete samples by traversing the samples beneath the beam using the $\mathrm{x}$ - and $\mathrm{y}$-axis of the CNC gantry table at speeds ranging from $60-600 \mathrm{~mm} / \mathrm{min}$. The laser optics were protected by means of a coaxially blown $\mathrm{O}_{2}$ shield gas jet a rate of $5 \mathrm{l} / \mathrm{min}$.

To determine the characteristics of the HPDL generated glazes on the treated OPC surface of concrete and the HPDL fired enamel, the samples were examined using optical microscopy, scanning electron microscopy (SEM), energy disperse X-ray analysis (EDX) and X-ray diffraction (XRD) techniques.

\section{Results}

\subsection{Operating window}

Fig. 1 schematically illustrates the HPDL OPC surface of concrete glazing and concrete enamelling operating windows in terms of traverse speed and power density. Within the optimum operating conditions good quality OPC and enamel glazes displaying few porosities and microcracks could be produced.

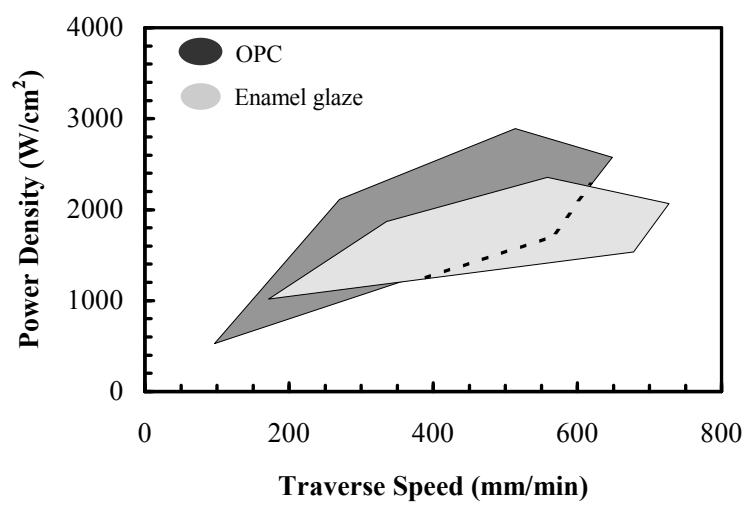

Fig. 1. Schematic representation of the operating window for the concrete glazing and enamelling process using the $120 \mathrm{~W}$ HPDL.

Furthermore, from Fig. 1 it is possible to ascertain the maximum enamelling rate that it may be possible to achieve using the HPDL. This was calculated as being $0.34 \mathrm{~m}^{2} / \mathrm{h}$ for a circular beam of $5 \mathrm{~mm}$ diameter with a laser power of $100 \mathrm{~W}$ and a traverse speed of $720 \mathrm{~mm} / \mathrm{min}$. 


\subsection{Morphological and microstructural characteristics}

\subsubsection{High power diode laser treated OPC surface}

The typical surface morphology of the glaze generated on the OPC surface of concrete when using the HPDL is shown in Fig. 2. As is evident from Fig. 2, crack and porosity formation were common features of the HPDL glaze. In addition, dramatic changes in the colour of the OPC surface were observed after HPDL treatment. Typically the OPC surface changed colour from grey to green.

The fracture section of the HPDL glaze generated on the OPC surface of concrete is shown in Fig. 3. As one can see from Fig. 3 , the microstructure of the HPDL generated glaze has no discernible structure and appears to be fully amorphous. Indeed, these findings were further confirmed by an XRD analysis of the HPDL generated glaze which revealed the HPDL induced glaze to be fully amorphous [14].

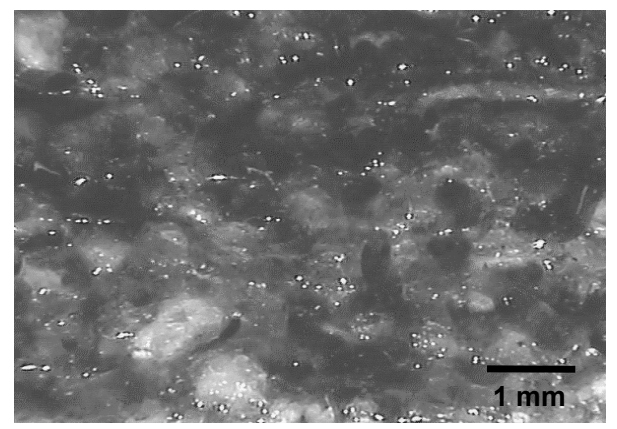

Fig. 2. Typical optical surface morphology of the HPDL generated OPC surface glaze. $\left(2.25 \mathrm{~kW} / \mathrm{cm}^{2}\right.$ power density, 240 $\mathrm{mm} / \mathrm{min}$ traverse speed)

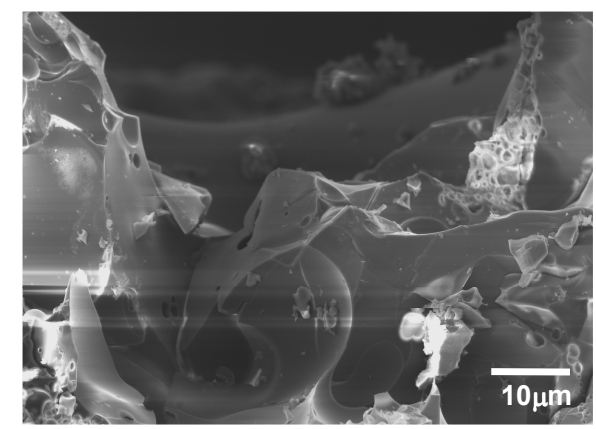

Fig. 3. Typical SEM micrograph of the fracture section of the HPDL generated OPC surface glaze. $\left(2.25 \mathrm{~kW} / \mathrm{cm}^{2}\right.$ power density, $240 \mathrm{~mm} / \mathrm{min}$ traverse speed)

Petzold et al. [29] have determined from differential thermal analysis (DTA) results that up to approximately $420^{\circ} \mathrm{C}$, OPC remains relatively stable. Notwithstanding this, some dehydration does occur and water is also lost from the pores of the cement. This is, however, far outweighed by the dehydration of $\mathrm{Ca}(\mathrm{OH})_{2}$ which follows shortly after $420^{\circ} \mathrm{C}$ is exceeded in accordance with

$\mathrm{Ca}(\mathrm{OH})_{2} \rightarrow \mathrm{CaO}+\mathrm{H}_{2} \mathrm{O}$

Furthermore the dehydration of the $\mathrm{Ca}(\mathrm{OH})_{2}$ promotes the development of microcracks which begin initially around the
$\mathrm{Ca}(\mathrm{OH})_{2}$ [30]. Moreover, this dehydration results in unslaked lime $(\mathrm{CaO})$, which is effectively the generated $\mathrm{HAZ}$; since the temperature of the surface of the OPC during interaction with both lasers during glazing was measured to be well in excess of $420^{\circ} \mathrm{C}$. This generated $\mathrm{CaO} \mathrm{HAZ}$ was observed located either below the glazed surface layer or around the edges of the glazes. Indeed, by using a phenolphthalein indicator followed by water misting, it was possible to clearly discern the HAZ around the HPDL treated zone on the OPC surface of the concrete, since phenolphthalein is an indicator which is colourless in $\mathrm{CaO}$, turning violet-red in the presence of $\mathrm{Ca}(\mathrm{OH})_{2}$ due to the change in $\mathrm{pH}$.

\subsubsection{High power diode laser fired enamel glaze}

It was observed that, prior to laser irradiation, it was not possible to fire the enamel onto the OPC surface of concrete. Indeed, HPDL interaction with the enamel when placed on the untreated OPC surface simply resulted in the 'balling' of the enamel (the formation of small spheres approximately the diameter of the laser beam itself). Such observations are in accord with those of Bourell et al. [31] and Agarwala et al. [32], who noted the balling phenomena during laser sintering work of silica based materials. After HPDL surface treatment of the OPC surface, however, it was possible to fire the enamel directly onto the OPC surface. The mechanism of this phenomena is based entirely on the wettability characteristics of the OPC surface.

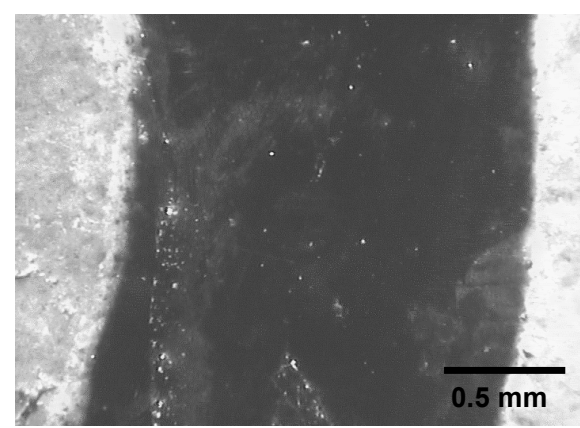

Fig. 4. Typical optical surface morphology of the HPDL fired enamel glaze on HPDL treated OPC. $\left(1.75 \mathrm{~kW} / \mathrm{cm}^{2}\right.$ power density, $360 \mathrm{~mm} / \mathrm{min}$ traverse speed)

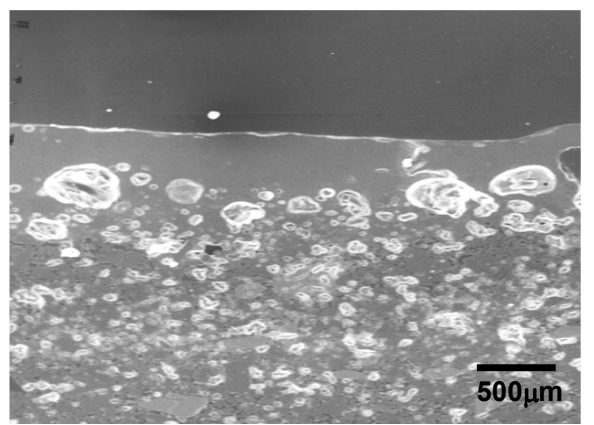

Fig. 5. Typical SEM micrograph of the cross-section of the HPDL fired enamel glaze on HPDL treated OPC. $\left(1.75 \mathrm{~kW} / \mathrm{cm}^{2}\right.$ power density, $360 \mathrm{~mm} / \mathrm{min}$ traverse speed)

The typical surface morphology of the HPDL fired enamel glaze produced on the HPDL treated OPC surface of concrete is 
shown in Fig. 4. As can be seen from Fig. 4, neither crack nor porosity formation were discernible on the enamel glaze. An XRD analysis of the HPDL fired enamel glaze revealed it to be fully amorphous.

The typical cross-sectional view of the HPDL fired enamel glaze produced on the HPDL treated OPC surface of concrete is shown in Fig. 5. As one can see from Fig. 5, the enamel glaze appears to be well bonded to the HPDL treated OPC surface of concrete.

Surface roughness measurements of the surfaces of the untreated OPC, the HPDL treated OPC and the HPDL fired enamel glaze were carried out. The investigation revealed that the average surface roughness of the HPDL fired enamel glaze was $0.21 \mu \mathrm{m}$. This compares with and average of $21.91 \mu \mathrm{m}$ for the untreated OPC surface and $2.88 \mu \mathrm{m}$ for the HPDL treated OPC surface. Clearly, this considerable improvement in the surface roughness of the OPC occasioned by HPDL enamelling makes the surface that much easier to clean and maintain.

\subsection{Mechanical, physical and chemical properties}

\subsubsection{Bond strength}

In order to ascertain the strength of the bond between the HPDL fired enamel glaze and the HPDL treated OPC surface, pull-off tests were conducted. For the tests the concrete was prepared as relatively small area samples $\left(25 \times 25 \mathrm{~mm}^{2}\right)$. High tensile aluminium test dollies were then attached onto the glazed surface and to the axially opposite concrete substrate surface using Araldite epoxy and left to cure for 24 hours. In order to ensure axial accuracy (essential for true results), the test dollies were set in position using identical V-blocks. The samples were placed into an Instron 4507 tensile/compressive test rig by mounting the test dollies into the jaws of the rig. A tensile force was then applied until failure with the energy being simultaneously recorded.

A post-test analysis of the samples showed that the material failed below the HPDL treated surface of the OPC in the HAZ. Within the optimum laser operating parameters the average bond strength of the glaze was recorded as $2.4 \mathrm{MPa}$. This compares with 6.3 MPa for the untreated OPC surface of concrete. Moreover, in all of the samples tested, not one failed an the interface between the HPDL fired enamel glaze and the HPDL treated OPC surface It is therefore reasonable to assert that the bond strength of the HPDL fired enamel glaze and the HPDL treated OPC surface is somewhat greater that $2.4 \mathrm{MPa}$.

\subsubsection{Rupture strength}

Tests were conducted to determine the rupture strength of the OPC glaze. Test samples were prepared as described above. The samples were placed onto the sample stage of the Instron 4507 tensile/compressive test rig and then subjected to a compressive rupture force until the OPC glaze failed (cracked), with the energy being simultaneously recorded. The rupture force was applied by means of a high tensile steel indentor with a $1 \mathrm{~mm}$ radius point. The results of the tests revealed that the average rupture strength of the HPDL fire enamel glaze was $2.8 \mathrm{~J}$ whilst the rupture strength of the untreated OPC surface was some $4.3 \mathrm{~J}$. The rupture strength of the HPDL treated OPC surface was measured as being only $0.8 \mathrm{~J}$.

\subsubsection{Wear resistance}

The wear resistance of a material in general is determined primarily by the hardness of the material in comparison with the hardness of other materials with which it comes into contact [33]. However, wear resistance does not always increase with hardness [34]. Tests were therefore conducted in accordance with Lawrence et al. [25] to determine the exact difference in wear resistance characteristics of the HPDL fired enamel glaze, the HPDL treated OPC surface and the untreated OPC surface. For experimental purposes the concrete was cut into smaller pieces $\left(25 \times 25 \mathrm{~mm}^{2}\right)$. Half of the samples were then laser treated, with half of the laser treated samples being enamelled. All the samples were then weighed and subjected to a friction force for 8 hours, being removed from the machine and weighed at intervals of $2 \mathrm{~h}$.

Fig. 6 shows the relationship between weight loss and the friction time for the OPC glaze and the untreated OPC. As one can see, the HPDL treated OPC surface shows a significant increase in wear resistance over the untreated OPC surface, with the weight loss being 2 times lower after 4 hours, and 3 times lower after 8 hours. What is more, the HPDL fired enamel glaze exhibits not only a much greater wear resistance than the untreated OPC surface, but a marked increase in wear resistance over the HPDL treated OPC surface.

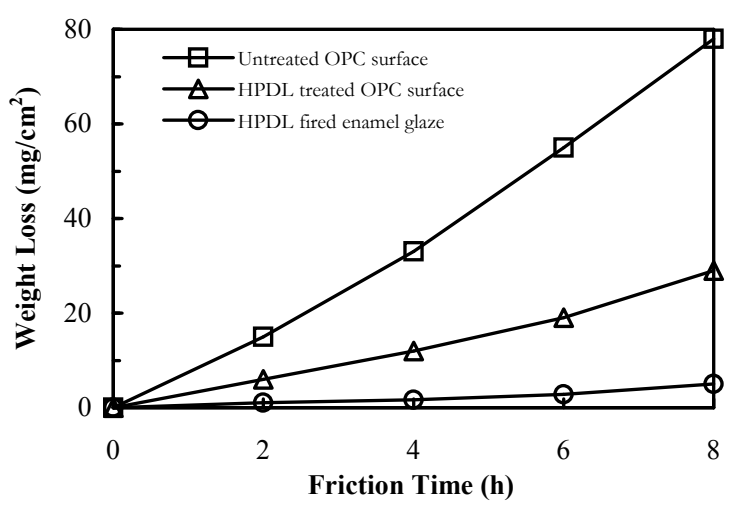

Fig. 6. Relationship between weight loss and friction time for the untreated OPC surface, the HPDL treated OPC surface and the HPDL generated glaze.

\subsubsection{Water sorptivity testing}

In order to test the water sorption properties of the HPDL fired enamel glaze, or in other words, the effect of the HPDL fired enamel glaze on the water absorption characteristics of the concrete, comparison experiments with both the untreated OPC surface and the HPDL treated OPC surface were conducted by measuring the water sorptivity. For the experiment the HPDL treated and untreated OPC samples were cut into smaller pieces $\left(25 \times 25 \mathrm{~mm}^{2}\right)$. The tests were conducted in accordance with the standard procedure as used by Hall et al. [35]. The samples were dried to a constant weight in an air oven at $65^{\circ} \mathrm{C}$ to ensure all pores were free of water. The surfaces of the samples were then immersed in water and weighed at regular intervals. The side faces of the three samples were shielded from the water by means of an Araldite coating. In order to determine the sorptivity, $i$ was plotted against the square root of time so as to give a straight line, as shown in Fig. 7. $i$ is defined as 
$i=\frac{\Delta m \cdot 1000}{A}$

where $\Delta m$ is the cumulative change in mass with time and $A$ is the absorbing surface area. The sorptivity, $S$, of the sample surfaces is simply the gradient of this line.

As is evident from Fig. 7, the sorptivity of the untreated OPC surface was a typical $0.096 \mathrm{~mm} / \mathrm{min}^{1 / 2}$, compared with 0.043 $\mathrm{mm} / \mathrm{min}^{1 / 2}$ for the HPDL treated OPC surface. It is therefore reasonable to conclude that since the HPDL treated OPC surface has half the sorption of the untreated OPC surface, then the HPDL treated OPC surface afforded the concrete twice as much resistance to water absorption than the untreated OPC surface. In addition, because the best-fit straight line for the HPDL treated OPC surface is below that of the untreated OPC surface, as well as intercepting the axis at a point below the untreated OPC surface, then it can be concluded that rate of absorption of the laser surface glazed concrete is much less than that of the untreated concrete. Furthermore, it is a distinct possibility that the $\mathrm{HAZ}$, which was identified as $\mathrm{CaO}$ resulting from the dehydration of the $\mathrm{Ca}(\mathrm{OH})_{2}$, may, once re-hydrated, act as a barrier towards liquids such as water, therefore augmenting the resistance of the HPDL treated OPC surface to water absorption. Moreover, as Fig. 7 shows, the sorptivity of the HPDL fired enamel glaze was practically zero. Thus, it is possible to assert that since the sorption of the HPDL fired enamel glaze is negligible, then the enamel glaze provides the untreated OPC surface of the concrete almost complete resistance to water absorption.

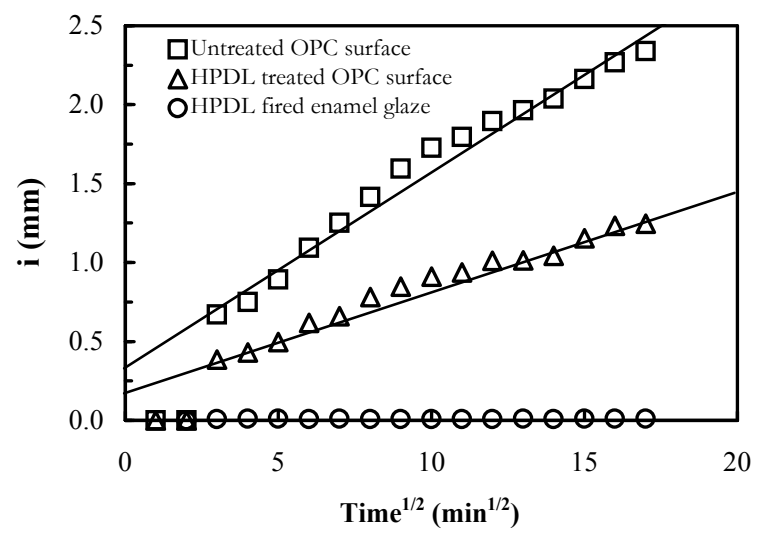

Fig. 7. Water absorption for the untreated OPC surface, the HPDL treated OPC surface and the HPDL fired enamel glaze.

\subsubsection{Corrosion resistance}

Concrete surfaces are often subjected to corrosive substances, either as part of the normal service environment and/or as a result of routine cleaning. Therefore corrosion resistance tests based upon BS 6431 [36] were conducted using nitric acid, sodium hydroxide and Premier Products MP9 detergent cleaner. The experiments were carried out by dropping small amounts of the corrosive agents in the concentration ratios of $80 \%, 60 \%, 40 \%$, $20 \%$ and $10 \%$ on to the surface of the untreated and HPDL glazed OPC surface of concrete at hourly intervals for four hours. The samples were then examined optically and mechanically tested in terms of compressive strength and wear. High concentrations of the various corrosive agents were used principally to accelerate the tests. However, in practice $60 \%$ nitric acid is used within the nuclear processing industry as a solvent for nuclear fuels [37].

All three substances in the concentrations $80 \%, 60 \%$ and $40 \%$ were seen to immediately attack the untreated OPC surface, with the nitric acid and sodium hydroxide attacking with greater severity than the detergent, whilst the HPDL glazed surface displayed no discernible microstructural changes or signs of devitrification due to corrosion.

Tests conducted according to ASTM C579-91 [38] revealed that exposure of the untreated OPC surface to the reagents had a significant effect on the compressive strength and the wear resistance of the OPC. Exposure of the OPC to nitric acid and sodium hydroxide in the concentrations $40-80 \%$ resulted in an average loss of compressive strength of approximately $19-37 \%$. In the case of the detergent a discernible loss in compressive strength only occurred with concentrations above $40 \%$. Here the average loss in compressive strength for concentrations in the range $60-80 \%$ was approximately $17 \%$. This compares with no discernible difference in either the wear resistance or the compressive strength of both the HPDL fired enamel glaze of the HPDL treated OPC surface.

Chemical attack also accounted for a large reduction in the wear resistance of the untreated OPC surface when exposed to the reagents with an $80 \%$ concentration. The wear resistance was significantly affected when the OPC was exposed to nitric acid and sodium hydroxide. Here the weight loss was approximately 5 times higher than for the unexposed OPC after $4 \mathrm{~h}$, and approximately 11 times higher after $8 \mathrm{~h}$ for the nitric acid. In the case of the detergent the weight loss was marginal after both 4 and $8 \mathrm{~h}$. No discernible change in the wear resistance of either the HPDL treated OPC surface of the HPDL fired enamel was observed.

\section{Discussion}

\subsection{OPC glaze formation mechanism}

The complex chemistry of the OPC surface of concrete and the hydration of its various constituents are a complex issue. Nonetheless, it is known that the constituents of OPC are minerals which exist as multi-component solid solution chemical compounds. Of particular importance with regards this study, OPC contains in relatively large proportions: $\mathrm{SiO}_{2}(21 \mathrm{wt} \%)$, $\mathrm{Al}_{2} \mathrm{O}_{3}(5 \mathrm{wt} \%)$ and $\mathrm{Fe}_{2} \mathrm{O}_{3}(3 \mathrm{wt} \%)$, which are basic glass network formers and modifiers. Consequently the intense local heating brought about by the incident HPDL beam results in melting of these compounds at around $1283^{\circ} \mathrm{C}$ [4], thereby causing the materials to lose the retained water and form an amorphous glassy material consisting of various calcium-silicate-alumina compounds [4]. Indeed, the amorphous nature of this glaze was verified by XRD analysis results given elsewhere [14].

As was mentioned earlier, HPDL interaction with the OPC surface occasioned a dramatic colour change; changing from grey to green. These changes are due to the resultant phase transitions and also, the presence in small concentrations of metal transition ions in various oxidation states within the OPC composition, in particular, ferric ions in the $\mathrm{Fe}^{3+}$ and $\mathrm{Fe}^{2+}$ oxidation state. $\mathrm{Fe}^{3+}$ and $\mathrm{Fe}^{2+}$ ions are known to give rise to green and blue colours respectively when subjected to intense heating [39, 40]. However, if both phases are present within the composition, then 
the colour is determined by the $\mathrm{Fe}^{3+} / \mathrm{Fe}^{2+}$ ion ratio, resulting in dark blue or black colours $[39,40]$. Since the surface produced after HPDL treatment was green, then it is reasonable to assume that both phases were not present within the OPC.

\subsection{Crack prevention in the enamel glaze}

As one can see from Fig. 4, cracking of the HPDL fired enamel glaze did not appear to occur. The absence of microcracks can be attributed mainly to tolerable thermal stresses generated during HPDL irradiation. In general, during the heating phase the stresses will be compressive and relieved by plastic deformation, thus precluding crack formation. At high temperatures $\left(T \geq T_{m}\right)$ the stresses can also be relieved [41-43]. However, during cooling when the temperature falls below $\mathrm{T}_{\mathrm{m}}$, stresses will then accumulate. If the fracture strength of the material is exceeded, then cracking within the melted layer will occur. The thermal stress $\sigma$, induced by a thermal gradient can be calculated using the Kingery equation:

$$
\sigma=\frac{E \alpha \Delta T}{1-v}
$$

where $E$ is Young's modulus, $\Delta T$ is the temperature change, $\alpha$ is the coefficient of thermal expansion and $v$ is Poisson's ratio. More succinctly, $\Delta T$ is the difference between the critical temperature (below which stresses can no longer be relieved) and ambient temperature. For the HPDL fired enamel glaze this is the difference between the melting point, $510^{\circ} \mathrm{C}$ and ambient temperature $20^{\circ} \mathrm{C}$. So, by using the following values for the enamel glaze [26]: $E=6.25 \times 10^{4} \mathrm{MN} / \mathrm{m}^{2}, \alpha=33 \times 10^{-7} \mathrm{~K}^{-1}$, $\Delta T=490^{\circ} \mathrm{C}$ and $v=0.162$, when the OPC surface of the concrete was irradiated by the HPDL beam the thermal stress produced in the resulting glass according to Eq. (3) was around $120 \mathrm{MN} / \mathrm{m}$. Since this is below the fracture strength of the enamel glaze, 135 $\mathrm{MN} / \mathrm{m}^{2}$ [26], cracking will not occur.

\subsection{Stability of the enamel glaze to devitrification}

Despite the fact that HPDL interaction with the enamel generated a fully amorphous glaze, it is possible for the enamel glaze to become crystalline through the destruction of the glassy state by means of a process known as devitrification. This can occur as either the breakdown of the glass surface by corrosion or weathering, or as a result of the overall composition remaining unchanged while the crystals separate in the glassy medium, therefore destroying the glassy state. This process being entirely dependant upon the temperature and composition of the glass. A further XRD analysis and a high magnification SEM examination of the enamel glaze produced no evidence of devitrification was observed within the OPC glaze.

As the findings of the corrosion testing work revealed, the HPDL fired enamel glaze displayed complete resistance to all three reactive agents, even at the highest concentrations. But, perhaps more importantly, even when exposed to the highest concentrations, no discernible microstructural changes or signs of devitrification due to corrosion were seen in either glaze. This is arguably a strong indication that the HPDL fired enamel glaze possesses an amorphous structure that provides more than adequate resistance to ageing and chemical attack. Furthermore, it can be asserted that the glass also did not devitrify as a result of favourable high temperatures and glass composition. This is of great significance since devitrification in this manner is the result of the movement of atoms to allow orientation and the presence of crystallisation centres. Such centres occur usually at the glass/air boundary, around a porosity [44]. Clearly, as Fig. 4 shows, porosities were in general not a common feature of the HPDL fired enamel glaze. Additionally, it is highly likely that the composition of the enamel glaze itself also played an important part in the stability to devitrification of the glaze. In particular it is known that compounds such as $\mathrm{Al}_{2} \mathrm{O}_{3}$ and $\mathrm{MgO}$ (which are present in abundance in the enamel glaze) are known to be very useful in assuaging devitrification problems [44]. This is because the inclusion of such compounds within the enamel glaze composition creates an glaze without a high liquidus temperature and therefore a reduced tendency towards devitrification [44].

\subsection{Wettability characteristics.}

The fact that it was not possible to HPDL fire the enamel glaze onto the OPC surface without prior HPDL treatment is due entirely to the wettability characteristics of the untreated and HPDL treated OPC surface. A full analysis of this phenomena is given elsewhere $[45,46]$. For this study it suffice to say that HPDL treatment of the OPC surface effected changes in the wettability characteristics of the OPC by melting and vitrifying the surface so that a more dense surface which was more polar in nature and that possessed an increased $\mathrm{O}_{2}$ content; factors that are known to improve the wettability characteristics of materials such as the $\mathrm{OPC}[22,24,26]$.

\subsection{Bonding characteristics}

Based on the nature of the attractive forces existing across a liquid-solid interface, wetting can be classified into the two broad categories of physical wetting and chemical wetting. In physical wetting the attractive energy required to wet a surface is provided by the reversible physical forces (van der Waals). In chemical wetting adhesion is achieved as a result of reactions occurring between the mating surfaces, giving rise to chemical bonds [47].

In practice, however, complex combinations of various bonding mechanisms actually occur, varying according to the types of materials used [47]. For the HPDL treated OPC surface and the enamel, the mechanisms involved in the bonding are principally: physical bonding (van der Waals forces), mechanical bonding, chemical bonding (oxide transformation and $\mathrm{O}_{2}$ bridging) and on a very small scale, electrochemical reactions such as the electrolytic (redox) effect due to the presence of ferric oxides within the HPDL treated OPC reacting with other oxides in the enamel [47]. Invariably, the preponderant bonding mechanisms between ceramic materials and enamels are physical and mechanical bonding [48]. Yet an EDX analysis conducted at the interface between the mild steel and the enamel revealed the presence of a small diffusion region which contained elements unique to both the HPDL treated OPC and the enamel. This is perhaps to be expected since enamel glazes on most materials are typically bonded as a result of some of the base material dissolving into the glaze [47], with wetting characteristics often being achieved or enhanced by a reaction at the interface at an elevated temperature (redox reaction) [49]. 
Table 1

Wear rate details and the nominal life increase of the HPDL fired enamel glaze over untreated OPC in various corrosive environments.

\begin{tabular}{ccccccc}
\hline & & & \multicolumn{3}{c}{ Wear Rate $\left(\mathrm{mg} / \mathrm{cm}^{2} / \mathrm{h}^{1}\right)$} & \\
\cline { 5 - 7 } & Density & Thickness & Unexposed & Detergent & $\mathrm{NaOH}$ & $\mathrm{HNO}_{3}$ \\
\hline Untreated OPC & $2220 \mathrm{~kg} / \mathrm{m}^{3}$ & $1500 \mu \mathrm{m}$ & 9.8 & 18.5 & 73.8 & 114.8 \\
HPDL fired enamel glaze & $2650 \mathrm{~kg} / \mathrm{m}^{3}$ & $750 \mu \mathrm{m}$ & 1.3 & 1.3 & 1.3 & 1.3 \\
\hline Increase in Wear Life & $\sim$ & $\sim$ & 4.5 & 8.5 & 33.9 & 52.7 \\
\hline
\end{tabular}

\subsection{Wear life characteristics}

As the results of the mechanical and chemical tests show, the HPDL fired enamel glaze out performed the untreated OPC surface in almost all the test areas. Moreover, the generally superior mechanical and chemical performance of the HPDL fired enamel glaze over the untreated OPC suggests that the life characteristics of the HPDL fired enamel glaze may also superior to those of untreated OPC. This was especially true in the case of chemical resistance and water absorptivity, where the HPDL fired enamel glaze proved to be resistant to both.

This marked variation in corrosion resistance and absorptivity performance is due to the difference in structure of the HPDL fired enamel glaze and the untreated OPC. Whereas the HPDL fired enamel glaze is of an amorphous nature, the untreated OPC is comprised of a porous polycrystalline structure, thus the untreated OPC is readily attacked by acids whilst the amorphous structure of the HPDL fired enamel glaze ensures an increase in acid resistance [48]. Yet in any analysis of the wear life of the two materials the in-situ relative thickness of the HPDL fired enamel glaze and the untreated OPC layer on concrete must be considered in order to give a true interpretation of the actual life characteristics, particularly when considering the wear resistance (with and without exposure to corrosive chemical agents). Consequently the increase in wear life can be given by

Increase in wear life $=\frac{\text { HPDL fired enamel glaze wear life }}{\text { Untreated OPC wear life }}$

where,

Wear life $=\frac{\text { Density } . \text { Thickness }\left(\mathrm{mg} \cdot \mathrm{cm}^{-3} \cdot \mathrm{cm}\right)}{\text { Wear rate }\left(\mathrm{mg} \cdot \mathrm{cm}^{-2} \cdot \mathrm{h}^{-1}\right)}$

Table 1 summarises the wear rate details and the nominal life increase of the HPDL fired enamel glaze over the untreated OPC surface in a variety of environments. To simulate service in a number of environments the untreated, laser treated and enamelled OPC surfaces were exposed prior to wear testing to a detergent, $\mathrm{NaOH}$ and $\mathrm{HNO}_{3}$. As Table 1 shows, the HPDL fired enamel glaze gives an increase in actual life over the untreated OPC surface regardless of the environment. However, as one can see, the increase in actual life of the HPDL fired enamel glaze over the untreated OPC surface varies considerably depending upon the working environment. But, notwithstanding this, arguably the most common working environment for an OPC surface would involve some contact with at least detergent acids, therefore yielding significant economic savings since a HPDL fired enamel glaze surface lasts around 4-times longer than one which is unglazed.

\section{Conclusions}

Using a $120 \mathrm{~W}$ high power diode laser (HPDL), the firing of a vitreous enamel frit to produce an enamel glaze on the ordinary Portland cement (OPC) surface of concrete was successfully demonstrated with power densities as low as $1 \mathrm{~kW} / \mathrm{cm}^{2}$ and at rates up to $780 \mathrm{~mm} / \mathrm{min}$. The glazes produced were typically 750 $\mu \mathrm{m}$ in thickness and displayed no discernible microcracks or porosities. A maximum coverage rate of $0.34 \mathrm{~m}^{2} / \mathrm{h}$ was calculated.

Owing to the wettability characteristics of the untreated OPC surface, it proved necessary to expose the surface of the OPC to HPDL radiation in order to fire the enamel. It is believed that this prior laser treatment effected changes in the wettability characteristics of the OPC by melting and vitrifying the surface so that a more dense surface which was more polar in nature and that possessed an increased $\mathrm{O}_{2}$ content; factors that are known to improve the wettability characteristics of materials such as the OPC.

Mechanical testing of the HPDL fired enamel glazes revealed that the average rupture strength of the HPDL fired enamel glaze was $2.8 \mathrm{~J}$, whilst the rupture strength of the untreated OPC surface was some $4.3 \mathrm{~J}$. The average bond strength of the glaze was recorded as $2.4 \mathrm{MPa}$. This compares with $6.3 \mathrm{MPa}$ for the untreated surface of the OPC. The HPDL fired enamel glaze exhibited exceptional resistance to chemical attack and water absorption, whilst the untreated OPC surface was highly susceptible to both.

Life assessment testing revealed that the HPDL fired enamel glaze effected an increase in wear life of 4.5 to 52.7 times over an untreated OPC surface, depending on the corrosive environment. Clearly, the economic and material benefits to be gained from the deployment of such an effective and efficient coating on OPC could be significant.

\section{References}

1. K. Sugita, M. Mori, T. Fujioka, Concrete Eng. 24 (1986) 13.

2. M. Hamasaki, Proc. of The International Symposium on Laser Processing, Boston, USA, 1987, 158.

3. H. Yoshizawa, S. Wignarajah, H. Saito, Trans. Japan Welding Soc. 20 (1989) 31.

4. L. Li, P.J. Modern, W.M. Steen, Proc. of LAMP '92, Osaka, Japan 1992, 843.

5. L. Li, W.M. Steen, P.J. Modern, Proc. of ISLOE '93, Singapore, 1994, 25.

6. L. Li, W.M. Steen, P.J. Modern, J.T. Spencer, Proc. of RECOD '94, London, UK, 1994, 24.

7. L. Li, W.M. Steen, P.J. Modern, J.T. Spencer, Proc. of EUROPTO '94: Laser Materials Processing and Machining, Munich, Germany, 1994, 84. 
8. K. Sugimoto, S. Wignarajah, K. Nagasi, S. Yasu, Proc. of ICALEO '90: Laser Materials Processing, Boston, USA, 1990, 302.

9. S. Wignarajah, K. Sugimoto, K. Nagai, Proc. of ICALEO '92: Laser Materials Processing, Orlando, USA, 1992, 383.

10. T.I. Borodina, G.E. Valyano, N.I. Ibragimov, E.P. Pakhomov, A.I. Romanov, L.G. Smirnova, P.K. Khabibulaev, J. Phys. and Chem. of Mater. Treatment, 25 (1995) 541.

11. J. Lawrence and L. Li, Proc. of ICALEO '99: Laser Materials Processing, Orlando, USA, 1999, 334.

12. J. Lawrence, L. Li, Mater. Sci. Eng. A, 284 (2000) 93.

13. J. Lawrence, L. Li, Mater. Sci. Eng. A, 287 (2000) 25.

14. J. Lawrence, L. Li, J. Laser Apps. 72 (2000) 8.

15. X.B. Zhou and J.Th.M. de Hosson, J. de Physique IV, 3 (1993) 1007.

16. X.B. Zhou and J.Th.M. de Hosson, Acta Metallurgica et Materialia, 42 (1994) 1155.

17. J. Heitz, E. Arenholz, T. Kefer, D. Bäuerle, H. Hibst and A. Hagemeyer, Appl. Phys. A, 55 (1992) 391.

18. F. Henari and W. Blau, Appl. Optics 34 (1995) 581.

19. M. Olfert, W. Duley and T. North, in: J. Mazumder (Ed.), Laser Processing, Kluwer Academic Publishing, Amsterdam 1996, pp. 479-490.

20. J. Lawrence and L. Li, J. Phys. D, 32 (1999) 2311.

21. J. Lawrence and L. Li, Appl. Surf. Sci. 154/155 (2000) 664.

22. J. Lawrence and L. Li, J. Phys. D, 32 (1999) 1075.

23. J. Lawrence, L. Li and J.T. Spencer, Proc. of ICALEO'96: Laser Materials Processing, Detroit, USA, 1996, 138.

24. J. Lawrence, L. Li and J.T. Spencer, Optics and Laser Tech. 30 (1998) 205.

25. J. Lawrence, L. Li and J.T. Spencer, Optics and Laser Tech. 30 (1998) 215.

26. J. Lawrence, $\mathrm{PhD}$ Thesis, University of Manchester Institute of Science \& Technology (UMIST), 1999.

27. J. Lawrence and L. Li, J. Mater. Process. Tech. (submitted).

28. J. Lawrence and L. Li, J. Eng. Manuf., Proc. IMechE, (accepted).

29. A. Petzold and M. Rohrs, Concrete for High Temperatures, MacLaren \& Sons, London, 1970, pp. 40-85.

30. Schneider and U. Diederichs, Betonwerk \& Fertigteil Technik 3 (1981) 141.
31. D.L. Bourell, H.L. Marcus, J.W. Barlow and J.J. Beaman, Int. J. Powder Metallurgy, 28 (1992) 369.

32. M. Agarwala, D.L. Bourell, J.J. Beaman, H.L. Marcus and J.W. Barlow, Rapid Prototyping J., 1 (1995) 26.

33. J.H. Dickson, Glass: A Handbook for Students and Technicians, Hutchinsons Scientific and Technical Publications, London, 1951, pp. 108-148.

34. A. Petitbon, L. Boquet, D. Delsart, Surf. \& Coat. Tech. 49 (1991) 57.

35. C. Hall, K.M. Tse, Building and Environment, 21 (1986) 113-118.

36. BS 6431: Part 19: 1984, Ceramic Wall and Floor Tiles: Method for Determination of Chemical Resistance. Glazed Tiles.

37. J.T. Spencer, Letter to Author, October 1997.

38. ASTM C597-91, Standards Test Method for Compressive Strength of Chemical-Resistant Mortars, Grouts, Monolithic Surfacings and Polymer Concretes.

39. G.D. Taylor, Construction Materials, Longman Scientific \& Technical, London, 1991, pp. 31-34.

40. N. Jackson and R.K. Dhir, Civil Engineering Materials, MacMillan Press, New York, 1992, pp. 90-92.

41. F.S. Galasso and R. Veltri, Ceramics Bull. 62 (1983) 253.

42. R. Sivakumar and B.L. Mordike, J. Surf. Eng. 4 (1988) 127.

43. J. Mazumder, Optical Eng. 30 (1991) 1208.

44. J.H. Dickson, Glass: A Handbook for Students and Technicians, Hutchinsons Scientific and Technical Publications, London, 1951, pp. 108-148.

45. J. Lawrence and L. Li, Surf. Coatings Tech., (submitted).

46. J. Lawrence and L. Li, J. Eng. Manuf., Proc. IMechE, (submitted).

47. V.A. Greenhut, in: H.F. Brinson (Ed.) Engineered Materials Handbook: Adhesives and Sealants, ASM International, Metals Park, 1991, pp. 298-311.

48. V.V. Vargin, Technology of Vitreous Enamels, Academic Press, New York, 1968, pp. 45-80.

49. J.A. Pask, and A.P. Tomisa, in: S.J. Schneider (Ed.), Engineered Materials Handbook: Ceramics and Glasses, ASM International, Metals Park, 1991, pp. 482-492. 